\title{
The Role of Anabolic Androgenic Steroids in Disruption of the Physiological Function in Discrete Areas of the Central Nervous System
}

\author{
Giuseppe Bertozzi $^{1}$ - Francesco Sessa ${ }^{1}$ - Giuseppe Davide Albano ${ }^{1} \cdot$ Gabriele Sani $^{2,3}$. \\ Francesca Maglietta ${ }^{1}$ - Mohsin H. K. Roshan ${ }^{4}$. Giovanni Li Volti ${ }^{5}$ - Renato Bernardini ${ }^{5}$. \\ Roberto Avola $^{5} \cdot$ Cristoforo Pomara $^{1,4,6}$ (D) Monica Salerno ${ }^{1}$
}

Received: 18 July 2017 / Accepted: 12 September 2017 /Published online: 2 October 2017

(C) The Author(s) 2017. This article is an open access publication

\begin{abstract}
Anabolic-androgenic steroids (AAS) abuse is often associated with a wide spectrum of adverse effects. These drugs are frequently abused by adolescents and athletes for esthetic purposes, as well as for improvement of their endurance and performances. In this literature review, we evaluated the correlation between AAS and anxiety or aggression. Two pathways are thought to be involved in AAS-induced behavioral disorders. Direct pathway via the amygdalo-fugal pathway, which connects the central nucleus of the amygdala to the brainstem, is involved in cognitive-emotive and homeostatic processes. The latter is modified by chronic AAS use, which subsequently leads to increased anxiety. Indirect pathways via the serotonergic, dopaminergic, and glutamatergic signals which are modified by AAS abuse in latero-anterior hypothalamus and can mediate the aggressive behavior. In conclusion, the molecular mechanisms underlying the
\end{abstract}

Cristoforo Pomara and Monica Salerno contributed equally to this work.

Cristoforo Pomara

cristoforo.pomara@unifg.it

1 Department of Clinical and Experimental Medicine, Section of Forensic Pathology, University of Foggia, Ospedale Colonnello D’Avanzo, Foggia, Italy

2 NESMOS Department (Neurosciences, Mental Health, and Sensory Organs), Sapienza University of Rome, School of Medicine and Psychology, Sant'Andrea Hospital, Rome, Italy

3 Centro Lucio Bini, Rome, Italy

4 Department of Anatomy, School of Medicine, University of Malta, Msida, Malta

5 Department of Biomedical and Biotechnological Sciences, University of Catania, Catania, Italy

6 D’Avanzo Hospital, 71122 Foggia, Italy behavioral alterations following AAS abuse is unclear and remains ambiguous as additional long-term studies aimed to understand the precise mechanisms are required.

Keywords Anabolic-androgenic steroids (AAS) · Abuse · Molecular mechanisms $\cdot$ Behavioral disorders $\cdot$ Amygdala . Central nervous system

\section{Introduction}

Anabolic-androgenic steroids (AAS) are testosterone-derived molecules which are often drug of abuse, and studies have shown their relation to a broad spectrum of side effects, including behavioral disorders [1]. With regard to this, at low concentrations, AAS has trivial effects on the mood, as well as perceived to be clinically beneficial when used in accordance with the treatment protocols for dysthymia and refractory depression. Nonetheless, at supraphysiological doses, AAS consumption is associated with depression, hypomania, or mania $[2,3]$. AAS-mediated behavior disorders may simply reflect the notable psychopathological comorbidity between drug addiction and disorders inducing neuroadaptive and neurotrophic changes in neural circuits [4]. Piacentino et al. suggested that the relationship between AAS use and psychopathology cannot be considered as a mere linear relationship, instead, it is considered to be more than a complex circuitry, driven by neuroendocrine mechanism, which involves different areas of the central nervous system (CNS) in addition to the involvement of the hypothalamic-pituitary-adrenal axis (HPA) [5]. AAS exert their pharmacological effects on the CNS in two distinctive ways: directly, by modulating their own intracellular receptors; and indirectly, by either influencing the binding site located on the neurotransmitter receptor or by causing the 
release of neuropeptides [6, 7]. These mechanisms are, thereby, affected by the expression of inhibitory GABA receptors and 5-HT receptors, which, among others, are abundantly expressed in areas of the brain associated with depression, stress, anger, and sexual behavior [8,9]. A number of studies have shown a significant interaction between 5-HTT-linked polymorphic region (5-HTTLPR) and neuroticism in athletes predisposed to anxiety and depression [10]. In addition, peripheral circulating AAS may be converted into estrogen derivatives, therefore, activating second messenger systems. Most AAS binds to androgen receptors and can also be aromatized to estrogenic metabolites which are, in turn, able to interact with both estrogen receptor-alpha $(\mathrm{ER} \alpha)$ and estrogen receptor-beta $(\mathrm{ER} \beta)$. Furthermore, AAS can also signal via the $\mathrm{ER} \alpha, \mathrm{ER} \beta$, and progesterone receptors, without being metabolically converted to estrogen [11]. Areas of the brain involved in the onset of anxiety and aggression associated with AAS abuse appear to have an affluent expression of steroid receptors and of enzymes involved in steroid synthesis and metabolism $[12,13]$. Cerebral structures involved in AAS-induced damage include the hypothalamus, basal ganglia, the amygdala, and the hippocampus. They allow the configuration of the underlying neurotransmitter/neuropeptidedriven integration network, which substantially contributes to anxiety- and aggressive-like behavior in animal model (Fig. 1). In details, the extended amygdala seems to play a major role in such mechanisms, and questions have been raised on its role in anxiety syndrome progression, particularly the involvement of subdivisions of the extended amygdala which includes the central amygdala (CeA) and bed nucleus of the stria terminalis (BnST). Furthermore, an imbalance in such relationship, mainly those involving the corticotropinreleasing hormone $(\mathrm{CRH})$ transcripts and GABAergic nerve endings, may mediate anxiogenic behavior in mice [14]. Moreover, the lateral hypothalamic area is activated during aggression following AAS administration and abuse [15,

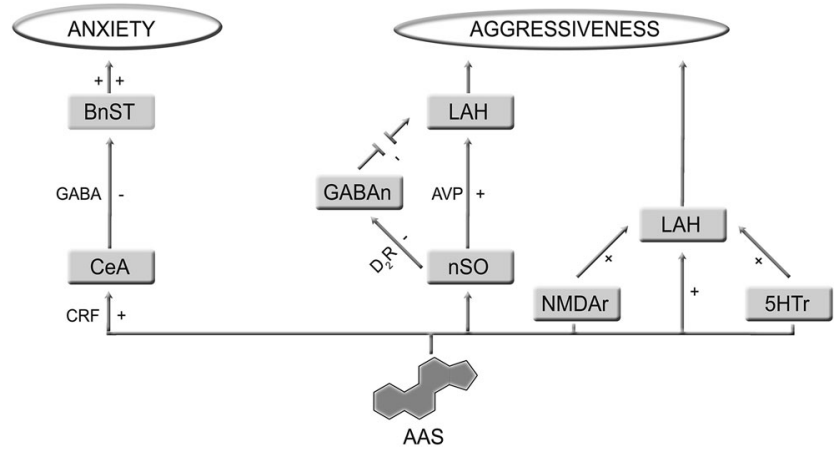

Fig. 1 Cerebral structure involved in AAS-induced damage and their connections. The pathway thought to determine AAS-induced behavioral disorders concerned the amygdalo-fugal signaling, which connects the central amygdala $(\mathrm{CeA})$ to bed nucleus of the stria terminalis (BnST) involves supraoptic neurons (nSO) and affects lateroanterior hypothalamus (LAH)
16]. Lateral hypothalamic is in fact regarded as the converging point where different neurotransmitters and their receptor converge to exert their effects. The result of such convergence between excitatory and inhibitory stimuli occurring at this level makes the lateral hypothalamus an ideal area to study the biological mechanisms underlying the induction of aggression occurring in AAS abusers.

Indeed, similar behavioral alterations in AAS abusers have been found and confirmed by the Center for Disease Control and Prevention (CDC), which reported that approximately two million individuals currently use or have used AAS in the USA, suggesting the AAS consumption is rapidly becoming pandemic worldwide [17]. Furthermore, Pope and Katz interviewed around 41 bodybuilders and football players, who were identified as AAS abusers. The prevalence of mood disorders was found in $22 \%$ of these individuals $[18,19]$. Other findings reported by $\mathrm{CDC}$ included $23 \%$ of athletes who were AAS abusers and met the Diagnostic and Statistical Manual of Mental Disorder III (DSM-III) criteria for mood disorders, including major depressive and bipolar disorders. In addition, such relationship was found to be significantly higher in athletes who took AAS regularly and at supraphysiological doses, compared to naïve athletes, exhibiting a prevalence of only $4 \%$ for major mood disorders [18]. Thus, it is reasonable to hypothesize that the AAS-related psychopathological syndrome is dose-dependent. Data correlating with such hypothesis was reported in a controlled retrospective study by Perry et al., which compared 20 regular AAS consuming male weightlifters to 20 non-AAS consuming male weightlifters, and showed that the formers exhibited a more depressive profile than the latter [20,21].

Moreover, symptoms were more prominent and clinically substantial in AAS users compared to non-AAS subjects. In addition, a survey conducted on a cohort of 479 athletes recruited via the Internet fitness forums, bodybuilding, weightlifting, and steroid websites showed that $16 \%$ of male AAS-dependent users had a history of DSM-IV-TR anxiety disorders, comprised of either generalized anxiety disorder (GAD), panic disorder, post-traumatic stress disorder (PTSD), obsessive-compulsive disorder (OCD), or social phobia [22]. Furthermore, in order to determine the age variability among the AAS consumers and abusers, Ip et al. recruited age-matched (40 or over) sportsmen and habitual steroid users, who admitted using AAS for non-fitness purposes. Results obtained from the study suggested that anxiety disorders were more prevalent among the AAS users, who were also engaged in aggressive alcohol use and polypharmacy compared to non-AAS users [23]. Likewise, Sato et al. described that AAS abuse in adolescence may alter the levels of androgens, which then predispose these individuals to an increased level of anxiety and altered response to stress [24].

AAS use has also been proven to unmask behavioral disorders, such as increased aggression, hostility, and 
unprovoked rage attacks. These emotional and behavioral outbursts have been referred to as "roid rage," defined as sudden and exaggerated aggression induced by AAS use which is prone to a subliminal provocation $[24,25]$. In addition, AAS users often suffer from a vigilant mindset accompanied by inability to adjust to situations, which then results in frustration and impulsiveness. Moreover, AAS use has also been associated to a wide range of violent crimes and domestic violence, particularly, physical abuse of the partner [5].

The aim of this literature review is to highlight the recent understanding and advances made regarding the mechanisms involved in AAS-induced disequilibrium in discrete areas of the brain, as well as to shed some light on the roles which neurotransmitters plays in the dysregulation process (Table 1), which then leads to substantial disruption of the physiological homeostasis and ultimately causes brain dysfunction and behavioral impairment.

\section{AAS and Cerebral Mechanisms on Anxiety}

Neural circuits involved in AAS-induced GAD are referred to as the extended amygdale [14]. It constitutes as the latter part of the limbic system and is composed of the CeA, the shell of the nucleus accumbens, and the BnST. Moreover, $\mathrm{CeA}$ has been postulated to be related to specific threat phasic fear. On the other hand, BnST has been considered to play an important role in sustained anxiety, since the disequilibrium between these two anatomical structures may lead to anxiety. The extended amygdala integrates cognitive-emotive and homeostatic processes by releasing an array of diverse neuromodulators, such as $\mathrm{CRH}$ and brain-derived neurotrophic factor, as well as neurotransmitters, including GABA, glutamate, serotonin (5HT), and dopamine [27, 28, 39-41].

Studies in male rat suggested that a prolonged exposure to AAS at supraphysiological doses may promote anxiety-like behavior, which is prevented or attenuated by intracerebroventricular injection of the CRH receptor type- 1 antagonist (antalarmin) [9]. This process was characterized by an enhanced GABAergic activity in neurons of the CeA, which thereby, exerted an inhibitory effect on BnST, in addition to being also inhibited by intracerebroventricular infusion of either alarmin, or $\mathrm{GABA}_{\mathrm{A}} \mathrm{R}-1$ antagonist picrotoxin. In addition, BnST activity can be sustained by $\mathrm{CRH}$ administration. This finding advocates a possible relationship exists between GABA, CRH, and anxiety-like behavior, at least in these experimental animal models. Furthermore, increased CRH mRNA transcription was also detected in CeA neurons after chronic AAS administration [42]. Therefore, the sequence of events leading to AAS-induced anxiogenic behavior is as following: AAS enhance CRHR-1-mediated presynaptic GABA release from $\mathrm{CeA}$ to $\mathrm{BnST}$; GABA modulates the activity of the CeA-BnST connection via an inhibitory pathway, and such disequilibrium then leads to anxiogenic behavior (Fig. 2) [43].

Nandrolone is one of the most common AAS used worldwide, possesses stimulatory properties for synaptic transmission, via $\mathrm{GABA}_{\mathrm{A}}$ receptors in the ventromedial nucleus of the hypothalamus but causes $\mathrm{GABA}_{\mathrm{A}}$ receptors to diminish in pre-optic areas. Furthermore, the increased release of neurons from CeA projecting to BnST and GABAergic-A receptormediated inhibition to BnST neurons has been associated to the development of aggression, stress, and anxiety [29, 44]. These effects are strictly related to the $\mathrm{GABA}_{\mathrm{A}}$ receptor, a pentameric transmembrane protein encoded by 16 different receptor subunit genes $(\alpha 1-\alpha 6, \beta 1-\beta 3, \gamma 1-\gamma 3, \delta, \varepsilon, \pi$, and $\theta$ ) [29]. Among the possible combinations, $\alpha 2$ subunitcontaining receptors seem to be highly expressed in the extended amygdala, where they appear to orchestrate the sequence of events that eventually leads the development of anxiety behavior. Indeed, an increase in GABAergic activity via the $\alpha 2$-containing receptors was evoked with the administration of $17 \alpha$-methyltestosterone, suggesting a possible direct allosteric modulation of these GABAergic receptors in the extended amygdala, which results in acute anxiolytic activities [30]. Furthermore, blockade and enhancement of synaptic conduction in dorsomedial hypothalamus is associated subsequently with anxiogenic responses and anxiolysis [45, 46]. However, modification of the physiological $\mathrm{GABA}_{\mathrm{A}}$-mediated neural signal is not easy nor does it occur so consistently, therefore, suggesting a key role of $\mathrm{GABA}_{\mathrm{A}}$ receptors in provoking anxiety-like disorders. The complex relationship between AAS and specific areas of the brain, such as hypothalamus, basal ganglia, amygdala, hippocampus, brain stem, spinal cord, and cerebral cortex, may reflect the involvement and interactions of a multi-neurotransmitter system which includes the serotonergic, glutamatergic, and dopaminergic pathways, subsequently leading to anxiety and aggression.

\section{AAS and Cerebral Mechanism of Aggressiveness}

Prolonged administration of AAS is associated with altered molecular expression of ER $\alpha$ or ER $\beta$ receptors in regions of the brain responsible for the control of aggression, and, among them, the important regions which lie within the latero-anterior hypothalamic area [15]. Furthermore, administration of AAS in animal model at given dose and time intervals reproduces the effects comparable to those seen in AAS abusers and induces changes in serotonergic, dopaminergic, and glutamatergic signaling, thus leading to anxiety-like behavior [4, 47].

The central serotonergic system has a pivotal role in the regulation of the activity of the central nervous system as well as influences a wide range of physiological and psychological processes, including the personality traits: for instance, low levels of 5-HT has been associated with impulsive aggression 


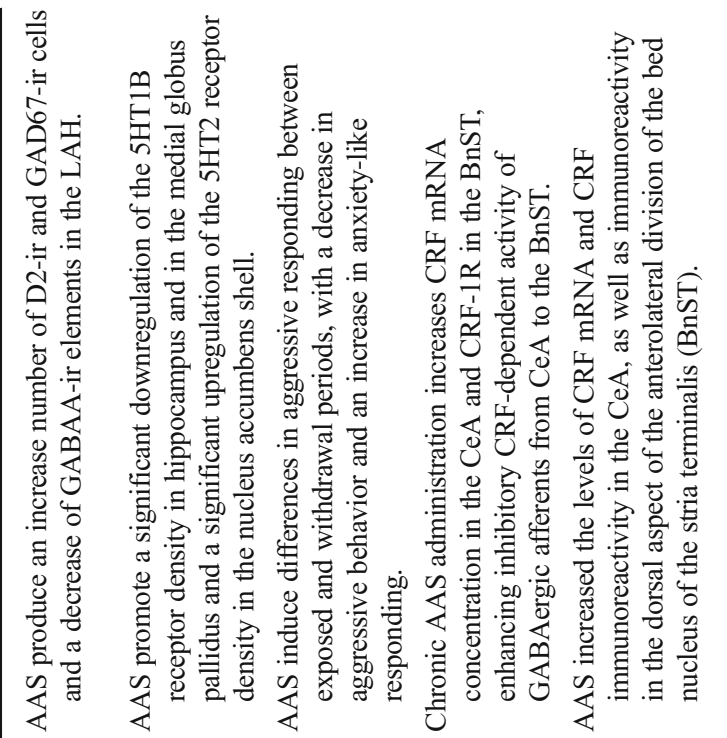

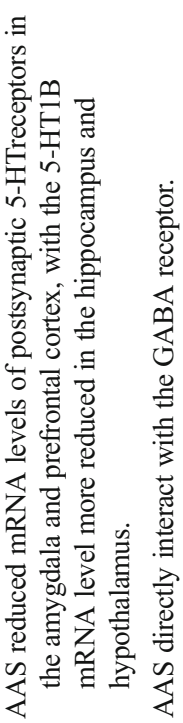

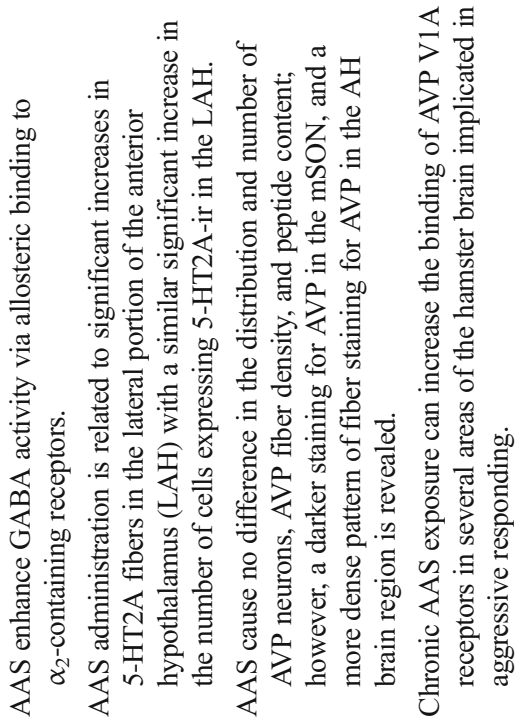

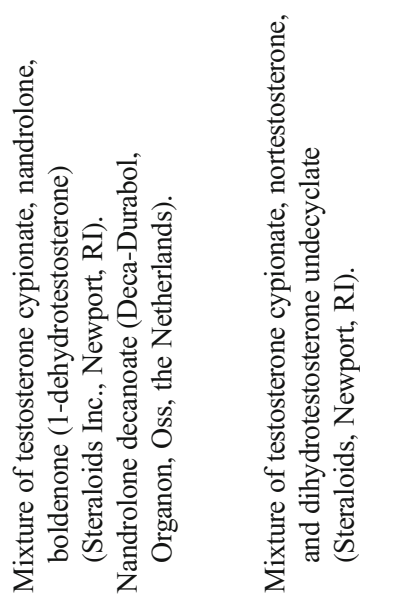

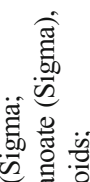

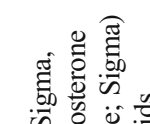

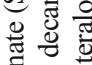

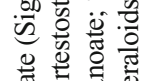

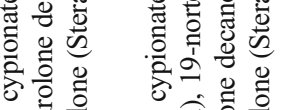

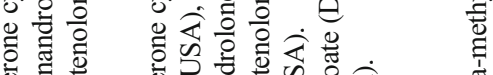

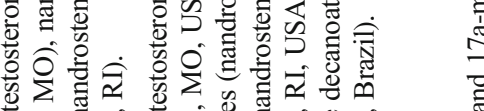

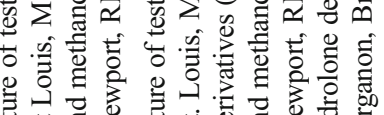

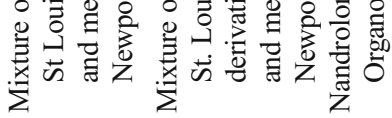

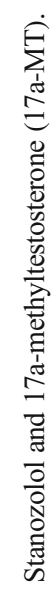

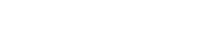

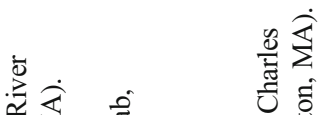

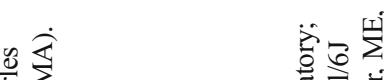

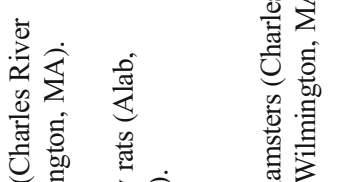

竞

密

害

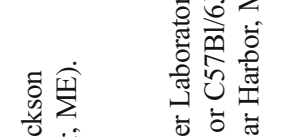

要

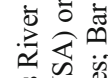

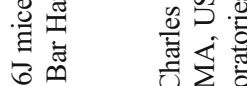

蛋

क

空.

突这苋

山े人

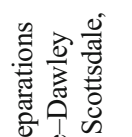

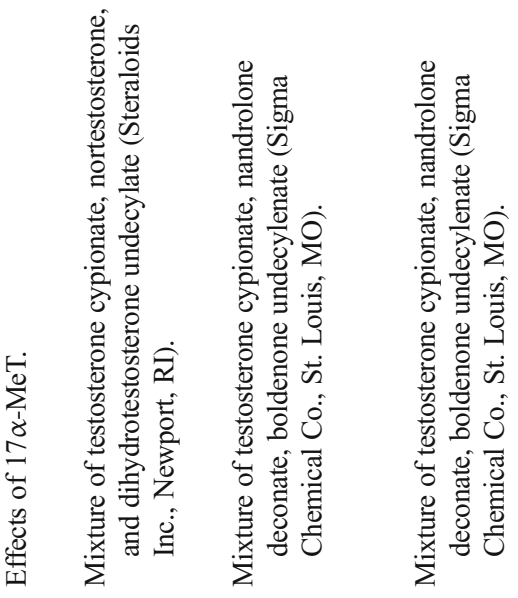

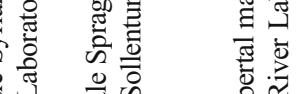

氜

要

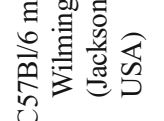

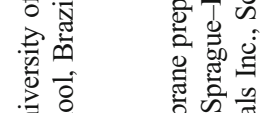

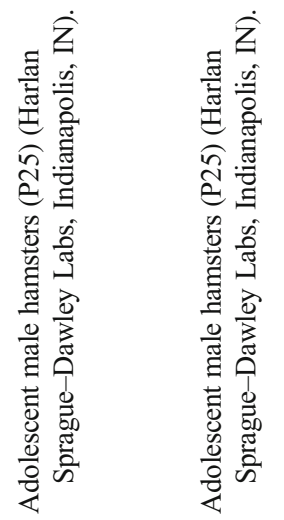

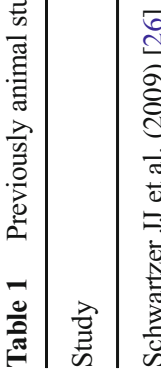

荡

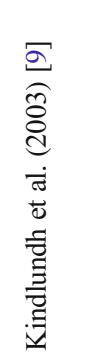

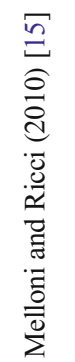

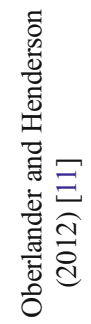

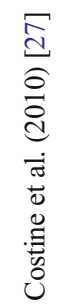

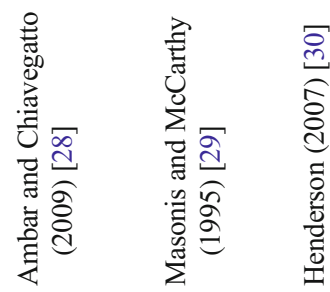

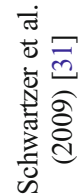

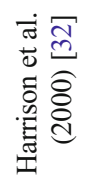

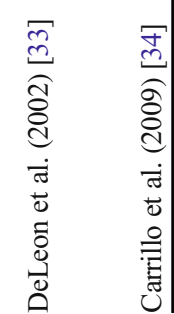




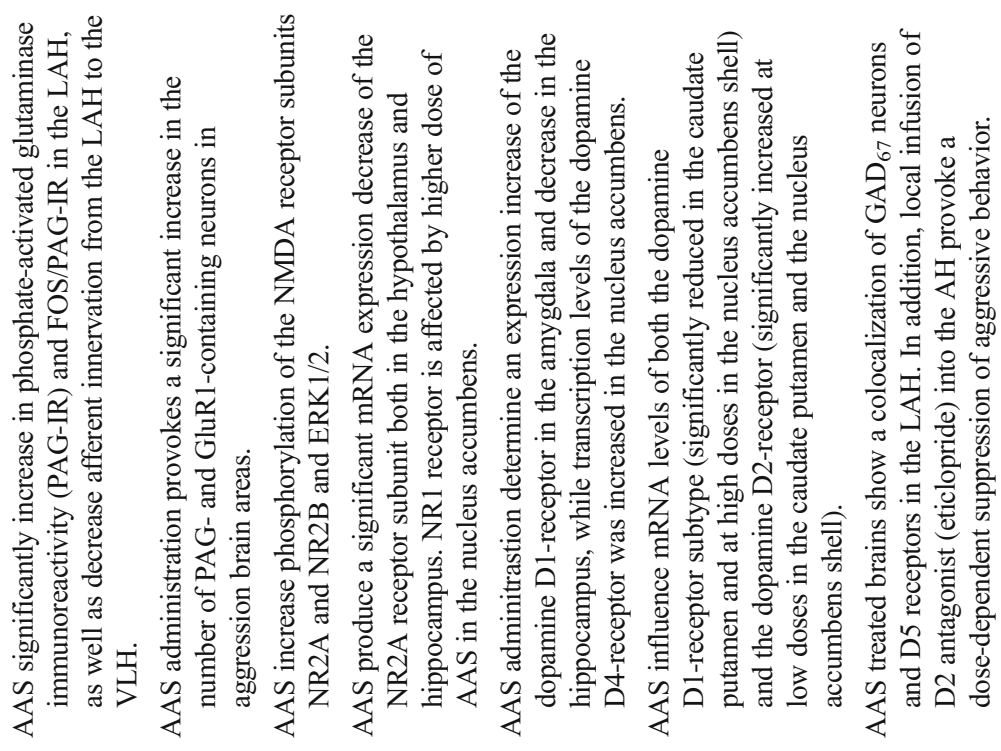

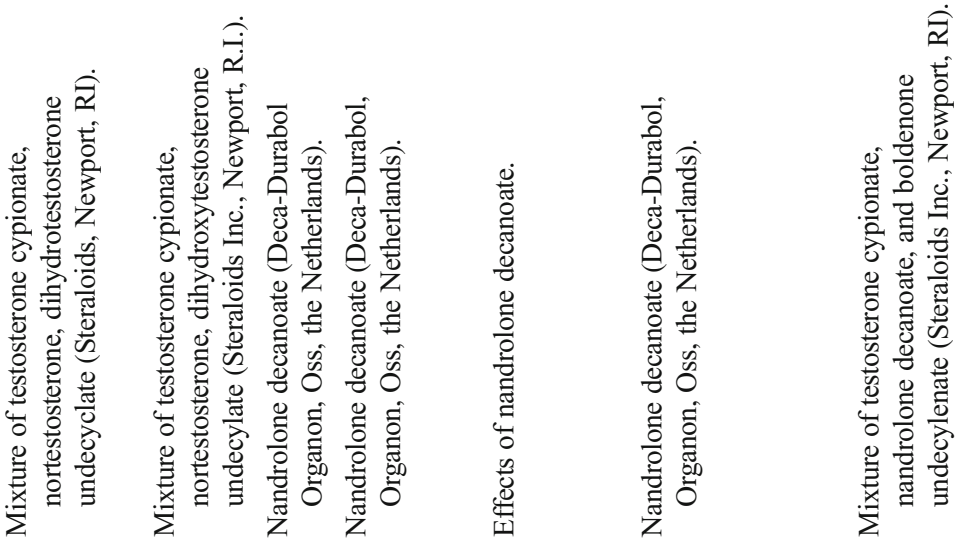

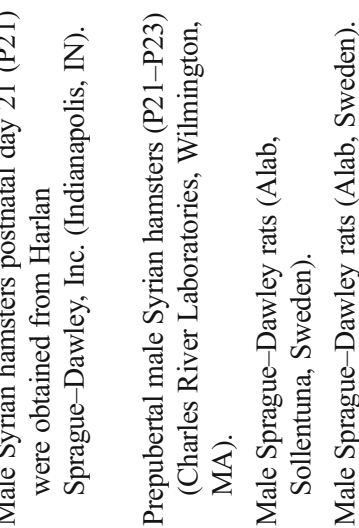

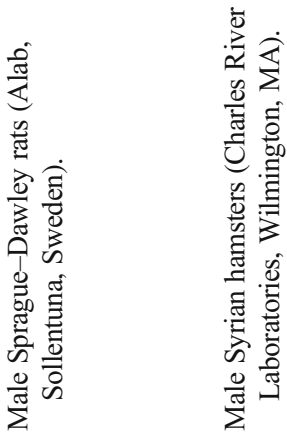

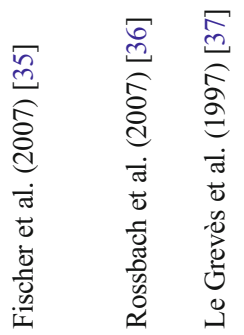

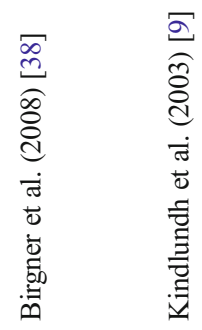

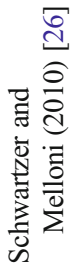




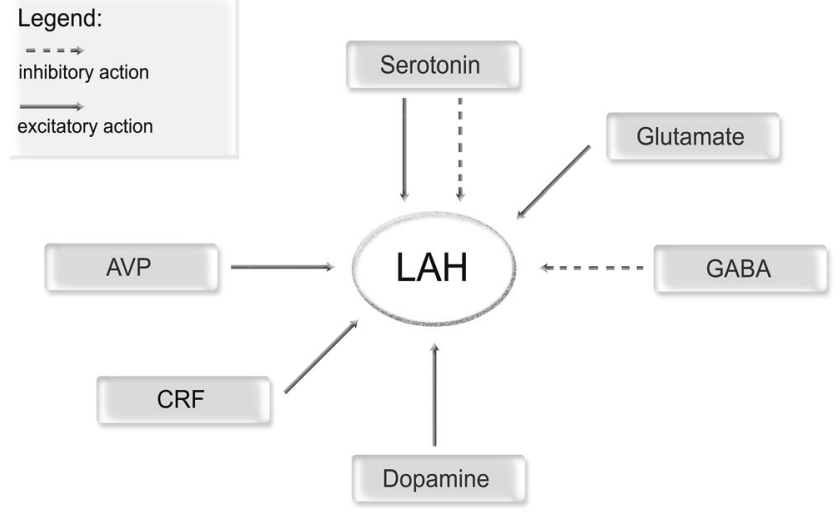

Fig. 2 Chronic administration of high doses of anabolic-androgenic steroids (AAS) promote anxiety-like behavior, through corticotrophin release factor (CRF) by enhancing GABAergic inhibitory effects from central amygdala $(\mathrm{CeA})$ onto bed nucleus of the stria terminalis $(\mathrm{BnST})$. Moreover, chronic AAS administration alters neurotransmitter expression involved in aggression control. AAS enhanced $\mathrm{D}_{2} \mathrm{R}$-mediated activation from supraoptic neurons (nSO) onto latero-anterior hypothalamus (LAH) and blocked GABA-mediated inhibition of AVP cells. In addition, AAS promote inverse relationship between $5-\mathrm{HT}_{1 \mathrm{~A}}-\mathrm{R}$-induced inhibition and $5-\mathrm{HT}_{2 \mathrm{~A}}-\mathrm{R}$-induced excitation, modifying their expression in hypothalamus. Finally, AAS are able to induce NMDA receptor phosphorylation in order to increase excitatory neurotransmission, resulting in an increment of aggression

in both human and animal studies [48]. Therefore, chronic AAS use may lead to a decrease in $5-\mathrm{HT}_{1 \mathrm{~A}}$ receptor (5$\mathrm{HT}_{1 \mathrm{~A}}-\mathrm{R}$ ) expression, as well as upregulation and increase activity of $5-\mathrm{HT}_{2 \mathrm{~A}}-\mathrm{R}$, in the same regions of the latero-anterior hypothalamus [31, 49]. Such reciprocal relationship between inhibition of the $5-\mathrm{HT}_{1 \mathrm{~A}}-\mathrm{R}$ and upregulation of $5-\mathrm{HT}_{2 \mathrm{~A}}-\mathrm{R}$ represents nearly the major contribution of AAS to the pathological development of aggression in the hypothalamus. Furthermore, $5-\mathrm{HT}_{1 \mathrm{~A}}-\mathrm{R}$ is located in the hippocampus, septum, amygdala, hypothalamus, and neocortex. The limbic system encompasses most of the latter areas and in fact is involved in modulating the emotional behavior. In addition, the presence of $5-\mathrm{HT}_{1 \mathrm{~A}}-\mathrm{R}$ in the neocortex suggests that 5$\mathrm{HT}_{1 \mathrm{~A}}-\mathrm{R}$ likely contributes to cortical cognitive and/or integrative functions. $5-\mathrm{HT}_{1 \mathrm{~A}}-\mathrm{R}$ is also amply expressed in both the dorsal and the median raphe nuclei, where they act as autoreceptors and modulates signal transmission of the serotonergic neurons. The 5- $\mathrm{HT}_{1 \mathrm{~B}}-\mathrm{R}$ is expressed exclusively in the rodent brain, whereas its analog $5-\mathrm{HT}_{1 \mathrm{D}}-\mathrm{R}$ is found in both bovine and humans. They are typically distributed in the dorsal raphe nucleus at the level of presynaptic terminals of serotonergic neurons, and they are thought to modulate serotonin release. In postsynaptic neurons, both $5-\mathrm{HT}_{1 \mathrm{~B}}-\mathrm{R}$ and $5-\mathrm{HT}_{1 \mathrm{D}^{-}}$ $\mathrm{R}$ modulates the release of other neurotransmitters, such as acetylcholine $(\mathrm{ACh})$ in the hippocampus and dopamine (DA) in the prefrontal cortex. On the other hand, 5- $\mathrm{HT}_{2 \mathrm{~A}}$ receptors are found in various cortical regions, particularly in the frontal cortex, as well as in discrete areas of the limbic system (Fig. 2).
Moreover, 5-HT neurons in the dorsal raphe nuclei have been hypothesized to interact with hypothalamic neurons to cause the release of vasopressin (AVP), in order to facilitate aggressiveness [15]. The cerebral regions primarily involved in aggressive behavior are located in the hypothalamus. Harrison et al. demonstrated that hamster exposed to AAS during adolescent is at risk of developing increased aggressive behavior, since AAS influences the anterior hypothalamicarginine vasopressin (AH-AVP) neural circuitry. It does so by increasing the AH-AVP fiber density and peptide content, which subsequently leads to an increase aggression intensity. In light of this, we may conclude that an existing underlying relationship between AAS exposure and AH-AVP expression and activity is needed to stimulate early onset of AASstimulated aggression [32]. Furthermore, early exposure of AAS in adolescents may increase vasopressin (1A) receptor binding in several significant areas of the hamster brain which may facilitate the aggressive behavior [33].

In addition, AAS consumption during adolescences may modify the physiological activity of the glutamatergic system in latero-anterior hypothalamus (LAH), a structure involved in development of aggressive behavior [34, 35]. Rossbach et al. demonstrated that AAS induces NMDA receptor phosphorylation that leads to an increase in excitatory neurotransmission in rodents, thereby, resulting in an increase aggression, impulsiveness, and irritability in both adult and adolescent rats [36]. NMDA and sigma receptor agonists, dehydroepiandrosterone sulfate, pregnenolone sulfate, and pregnenolone sulfate used in other studies managed to displace the natural receptor agonists from both sigma- 1 and sigma- 2 sites. Chronic nandrolone administration, on the other hand, only managed to alter the affinity of the sigma- 1 receptor, but not of the sigma- 2 receptor [50].

NMDA receptor is a heterotetramer, consisting of different subunits, which are comprised of one GluN1 subunit, four GluN2 subunits (GluN2A, GluN2B, GluN2C, and GluN2D) encoded by four different genes. The two GluN3 subunits (GluN3A and GluN3B) are encoded by two different genes. Moreover, the NMDAR structure is typically formed by a GluN1 and GluN2 subunits or by a combination of both GluN2 and GluN3 subunits [51]. A recent study by Le Grevès et al. suggested that AAS administration induced the following alterations: a decrease in mRNA expression of NR2A receptor subunits both in hypothalamus and hippocampus; a decrease in mRNA expression of NR2B receptor in hypothalamus [37]. Reduced expression of both NR2A and NR2B receptors in hippocampus and hypothalamus are suggested to be involved in the underlying the mechanisms which leads to the onset of aggressive behavior.

Finally, other mediator involved in AAS-induced aggression seems to the dopamine receptors, whose role has been highlighted in a number of in vivo studies $[4,52]$. Evidence shows that dopamine $D_{2}$ receptor $\left(D_{2} R\right)$ located in the $L A H$ 
directly modulate AAS-induced aggression in post-pubertal age. In addition, $D_{5}$ receptors $\left(D_{5} R\right)$ have been indirectly linked to AAS-induced aggression. Likewise, dopamine released from LAH has been proven to influence GABAergic neurons via the inhibitory $\mathrm{D}_{2} \mathrm{R}$; non-GABAergic neurons through the $\mathrm{D}_{5}$ receptor-mediated stimulation. Remarkably, $\mathrm{D}_{5} \mathrm{R}$ staining pattern observed in the LAH was similar to glutamatergic neurons pattern, since hypothalamus is densely populated with excitatory $\mathrm{D}_{5} \mathrm{R}$ and dopamine innervation to LAH after AAS exposure may facilitate aggression via the $\mathrm{D}_{5} \mathrm{R}[38,53]$. Moreover, dopamine release may influence glutamatergic neuron function across the neuraxis [54-56]. Moreover, Schwartzer et al. hypothesized that chronic AAS abuse may increase $\mathrm{D}_{2} \mathrm{R}$ activation in the LAH, and, thereby, inhibit GABA-mediated inhibition of AVP cells. Such $\mathrm{D}_{2} \mathrm{R}$ over stimulation finally results in the exacerbation of the aggressive behavior frequently observed in AAS abusers [4]. This hypothesis is supported by a number of studies suggesting that dopamine receptors particularly D2R and D5R activation triggers depolarization of neurons in the supraoptic nucleus of the hypothalamus [26]. Together with other neuromodulators, both dopaminergic pathways and activation of hypothalamic pathways forms the basis of AAS-related aggressiveness which is summarized in Fig. 3 [57].

Behind neurotransmitters, the redox status may also explain AAS-neurotoxicity. Indeed, Bueno et al. proved that different doses and periods of boldenone and stanazolol administration can change reactive oxygen species (ROS) levels in cerebral cortex and hippocampus [58]. Boldenone was also able to increase acetylcholinesterase (AChE) activity. This effect allowed suggesting that cholinergic system can be

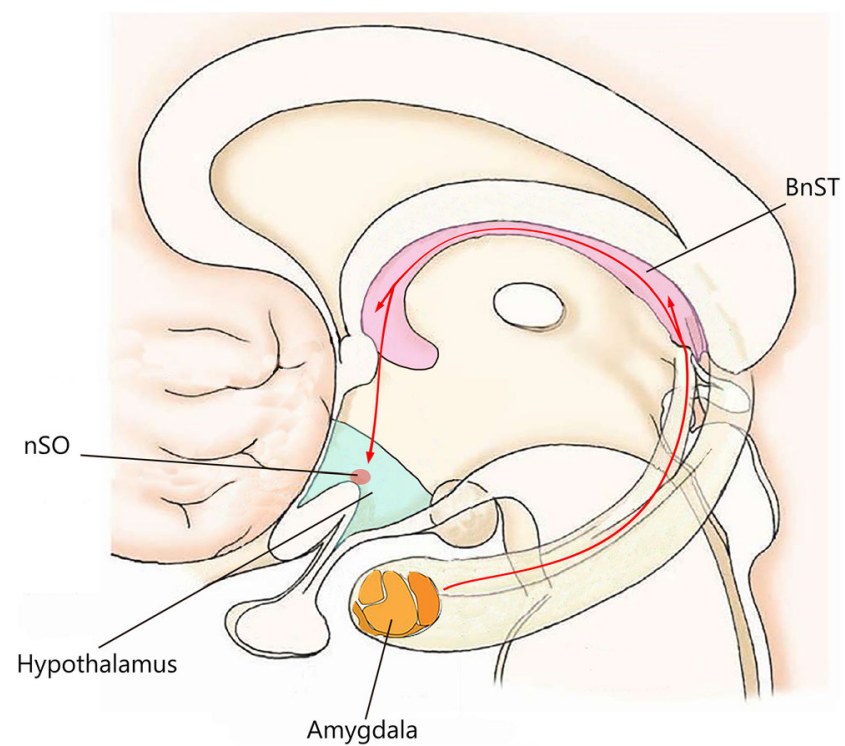

Fig. 3 AAS-mediated neurotransmitter release and their action on lateroanterior hypothalamus (LAH): two different arrows are used to indicate inhibitory and excitatory action on LAH. These pathways are useful to clarify the AAS action on human behavior involved through the stimulation of presynaptic nicotinic acetylcholine receptors and consequently release of glutamate, GABA, dopamine, acetylcholine, norepinephrine, and serotonin. This mechanism could explain the increased aggressivelike behavior and territorial dominance [58].

\section{Conclusions}

Considering the high prevalence and the increased frequency of AAS abuse documented worldwide and the detrimental effects of AAS on the behavior of users and their families is rapidly becoming a serious public health concern. The understanding of the precise underlying mechanisms and the pathophysiology of AAS-induced neuropsychiatric disorders is relatively recent and appears to be related to chronic AAS exposure. This subsequently leads to the development of anxiety and aggressive behavior. In order to prevent the onset of these symptoms, or to implement curative measures in chronic AAS abusers, a better understanding of the organic and functional processes involved in these psychiatric symptoms is required. Illicit AAS use and the related psychiatric symptoms may take a longer time to resolve, since other illicit substances such as alcohol and class A drugs are often also abused, especially in those with depression. In conclusion, AAS abuse is a global issue and requires more immediate primary and secondary prevention, which is only possible though more longterm research.

Open Access This article is distributed under the terms of the Creative Commons Attribution 4.0 International License (http:// creativecommons.org/licenses/by/4.0/), which permits unrestricted use, distribution, and reproduction in any medium, provided you give appropriate credit to the original author(s) and the source, provide a link to the Creative Commons license, and indicate if changes were made.

\section{References}

1. Pomara C, Neri M, Bello S, Fiore C, Riezzo I, Turillazzi E (2015) Neurotoxicity by synthetic androgen steroids: oxidative stress, apoptosis, and neuropathology: a review. Curr Neuropharmacol 13(1): 132-145. https://doi.org/10.2174/1570159X13666141210221434

2. Amiaz R, Seidman SN (2008) Testosterone and depression in men. Curr Opin Endocrinol Diabetes Obes 15(3):278-283. https://doi. org/10.1097/MED.0b013e3282fc27eb

3. Zarrouf FA, Artz S, Griffith J, Sirbu C, Kommor M (2009) Testosterone and depression: systematic review and meta-analysis. J Psychiatr Pract 15(4):289-305. https://doi.org/10.1097/01.pra. 0000358315.88931.fc

4. Schwartzer JJ, Ricci LA, Melloni RH Jr (2009) Interactions between the dopaminergic and GABAergic neural systems in the lateral anterior hypothalamus of aggressive AAS-treated hamsters. Behav Brain Res 203(1):15-22. https://doi.org/10.1016/j.bbr.2009. 04.007 
5. Piacentino D, Kotzalidis GD, Del Casale A, Aromatario MR, Pomara C, Girardi P, Sani G (2015) Anabolic-androgenic steroid use and psychopathology in athletes. A systematic review. Curr Neuropharmacol 13(1):101-121. https://doi.org/10.2174/ 1570159X13666141210222725

6. Masonis AE, McCarthy MP (1996) Effects of the androgenic/ anabolic steroid stanozolol on GABAA receptor function: GABA-stimulated 36Cl- influx and [35S] TBPS binding. J Pharmacol Exp Ther 279(1):186-193

7. Hughes TK Jr, Rady PL, Smith EM (1998) Potential for the effects of anabolic steroid abuse in the immune and neuroendocrine axis. $\mathrm{J}$ Neuroimmunol 83(1-2):162-167

8. McIntyre KL, Porter DM, Henderson LP (2002) Anabolic androgenic steroids induce age-, sex-, and dose-dependent changes in GABA(A) receptor subunit mRNAs in the mouse forebrain. Neuropharmacology 43(4):634-645

9. Kindlundh AM, Lindblom J, Bergstrom L, Nyberg F (2003) The anabolic-androgenic steroid nandrolone induces alterations in the density of serotonergic 5HT1B and 5HT2 receptors in the male rat brain. Neuroscience 119(1):113-120

10. Petito A, Altamura M, Iuso S, Padalino FA, Sessa F, D'Andrea G, Margaglione M, Bellomo A (2016) The relationship between personality traits, the 5HTT polymorphisms, and the occurrence of anxiety and depressive symptoms in elite athletes. PLoS One 11(6):e0156601. https://doi.org/10.1371/journal.pone.0156601

11. Oberlander JG, Porter DM, Penatti CA, Henderson LP (2012) Anabolic androgenic steroid abuse: multiple mechanisms of regulation of GABAergic synapses in neuroendocrine control regions of the rodent forebrain. J Neuroendocrinol 24(1):202-214. https://doi. org/10.1111/j.1365-2826.2011.02151.x

12. Pinna G, Agis-Balboa RC, Pibiri F, Nelson M, Guidotti A, Costa E (2008) Neurosteroid biosynthesis regulates sexually dimorphic fear and aggressive behavior in mice. Neurochem Res 33(10):19902007. https://doi.org/10.1007/s11064-008-9718-5

13. Ostlund H, Keller E, Hurd YL (2003) Estrogen receptor gene expression in relation to neuropsychiatric disorders. Ann N Y Acad Sci 1007:54-63

14. Davis M, Walker DL, Miles L, Grillon C (2010) Phasic vs sustained fear in rats and humans: role of the extended amygdala in fear vs anxiety. Neuropsychopharmacology 35(1):105-135. https://doi. org/10.1038/npp.2009.109

15. Melloni RH Jr, Ricci LA (2010) Adolescent exposure to anabolic/ androgenic steroids and the neurobiology of offensive aggression: a hypothalamic neural model based on findings in pubertal Syrian hamsters. Horm Behav 58(1):177-191. https://doi.org/10.1016/j. yhbeh.2009.11.002

16. Tibullo D, Barbagallo I, Giallongo C, La Cava P, Parrinello N, Vanella L, Stagno F, Palumbo GA et al (2013) Nuclear translocation of heme oxygenase- 1 confers resistance to imatinib in chronic myeloid leukemia cells. Curr Pharm Des 19(15):2765-2770

17. Pope HG Jr, Kanayama G, Athey A, Ryan E, Hudson JI, Baggish A (2014) The lifetime prevalence of anabolic-androgenic steroid use and dependence in Americans: current best estimates. Am J Addict 23(4):371-377. https://doi.org/10.1111/j.1521-0391.2013.12118.x

18. Pope HG Jr, Katz DL (1994) Psychiatric and medical effects of anabolic-androgenic steroid use. A controlled study of 160 athletes. Arch Gen Psychiatry 51(5):375-382

19. Salomone F, Barbagallo I, Puzzo L, Piazza C, Li Volti G (2013) Efficacy of adipose tissue-mesenchymal stem cell transplantation in rats with acetaminophen liver injury. Stem Cell Res 11(3):10371044. https://doi.org/10.1016/j.scr.2013.07.003

20. Perry PJ, Tsuang MT, Hwang MH (1984) Prednisolone psychosis: clinical observations. Drug Intell Clin Pharm 18(7-8):603-609

21. Li Volti G, Salomone S, Sorrenti V, Mangiameli A, Urso V, Siarkos I, Galvano F, Salamone F (2011) Effect of silibinin on endothelial dysfunction and ADMA levels in obese diabetic mice. Cardiovasc Diabetol 10:62. https://doi.org/10.1186/1475-2840-10-62

22. Oberlander JG, Henderson LP (2012) Corticotropin-releasing factor modulation of forebrain GABAergic transmission has a pivotal role in the expression of anabolic steroid-induced anxiety in the female mouse. Neuropsychopharmacology 37(6):1483-1499. https://doi.org/10.1038/npp.2011.334

23. Ip EJ, Trinh K, Tenerowicz MJ, Pal J, Lindfelt TA, Perry PJ (2015) Characteristics and behaviors of older male anabolic steroid users. $J$ Pharm Pract 28(5):450-456. https://doi.org/10.1177/ 0897190014527319

24. Sato SM, Schulz KM, Sisk CL, Wood RI (2008) Adolescents and androgens, receptors and rewards. Horm Behav 53(5):647-658. https://doi.org/10.1016/j.yhbeh.2008.01.010

25. Malone DA Jr, Dimeff RJ, Lombardo JA, Sample RH (1995) Psychiatric effects and psychoactive substance use in anabolicandrogenic steroid users. Clin J Sport Med 5(1):25-31

26. Schwartzer JJ, Melloni RH Jr (2010) Dopamine activity in the lateral anterior hypothalamus modulates AAS-induced aggression through D2 but not D5 receptors. Behav Neurosci 124(5):645655. https://doi.org/10.1037/a0020899

27. Costine BA, Oberlander JG, Davis MC, Penatti CA, Porter DM, Leaton RN, Henderson LP (2010) Chronic anabolic androgenic steroid exposure alters corticotropin releasing factor expression and anxiety-like behaviors in the female mouse. Psychoneuroendocrinology 35(10):1473-1485. https://doi.org/10. 1016/j.psyneuen.2010.04.015

28. Ambar G, Chiavegatto S (2009) Anabolic-androgenic steroid treatment induces behavioral disinhibition and downregulation of serotonin receptor messenger RNA in the prefrontal cortex and amygdala of male mice. Genes Brain Behav 8(2):161-173. https://doi. org/10.1111/j.1601-183X.2008.00458.x

29. Masonis AE, McCarthy MP (1995) Direct effects of the anabolic/ androgenic steroids, stanozolol and 17 alpha-methyltestosterone, on benzodiazepine binding to the gamma-aminobutyric acid(a) receptor. Neurosci Lett 189(1):35-38

30. Henderson LP (2007) Steroid modulation of GABAA receptormediated transmission in the hypothalamus: effects on reproductive function. Neuropharmacology 52(7):1439-1453. https://doi.org/10. 1016/j.neuropharm.2007.01.022

31. Schwartzer JJ, Ricci LA, Melloni RH Jr (2009) Adolescent anabolic-androgenic steroid exposure alters lateral anterior hypothalamic serotonin-2A receptors in aggressive male hamsters. Behav Brain Res 199(2):257-262. https://doi.org/10.1016/j.bbr. 2008.11.048

32. Harrison RJ, Connor DF, Nowak C, Nash K, Melloni RH Jr (2000) Chronic anabolic-androgenic steroid treatment during adolescence increases anterior hypothalamic vasopressin and aggression in intact hamsters. Psychoneuroendocrinology 25(4):317-338

33. DeLeon KR, Grimes JM, Melloni RH Jr (2002) Repeated anabolicandrogenic steroid treatment during adolescence increases vasopressin V(1A) receptor binding in Syrian hamsters: correlation with offensive aggression. Horm Behav 42(2):182-191

34. Carrillo M, Ricci LA, Melloni RH Jr (2009) Adolescent anabolic androgenic steroids reorganize the glutamatergic neural circuitry in the hypothalamus. Brain Res 1249:118-127. https://doi.org/10. 1016/j.brainres.2008.10.053

35. Fischer SG, Ricci LA, Melloni RH Jr (2007) Repeated anabolic/ androgenic steroid exposure during adolescence alters phosphateactivated glutaminase and glutamate receptor 1 (GluR1) subunit immunoreactivity in Hamster brain: correlation with offensive aggression. Behav Brain Res 180(1):77-85. https://doi.org/10.1016/j. bbr.2007.02.025

36. Rossbach UL, Steensland P, Nyberg F, Le Greves P (2007) Nandrolone-induced hippocampal phosphorylation of NMDA 
receptor subunits and ERKs. Biochem Biophys Res Commun 357(4):1028-1033. https://doi.org/10.1016/j.bbrc.2007.04.037

37. Le Greves P, Huang W, Johansson P, Thornwall M, Zhou Q, Nyberg $F$ (1997) Effects of an anabolic-androgenic steroid on the regulation of the NMDA receptor NR1, NR2A and NR2B subunit mRNAs in brain regions of the male rat. Neurosci Lett 226(1):61-64

38. Birgner C, Kindlundh-Hogberg AM, Oreland L, Alsio J, Lindblom J, Schioth HB, Bergstrom L (2008) Reduced activity of monoamine oxidase in the rat brain following repeated nandrolone decanoate administration. Brain Res 1219:103-110. https://doi.org/10.1016/j. brainres.2008.05.014

39. Matrisciano F, Modafferi AM, Togna GI, Barone Y, Pinna G, Nicoletti F, Scaccianoce S (2010) Repeated anabolic androgenic steroid treatment causes antidepressant-reversible alterations of the hypothalamic-pituitary-adrenal axis, BDNF levels and behavior. Neuropharmacology 58(7):1078-1084. https://doi.org/10. 1016/j.neuropharm.2010.01.015

40. Kash TL, Winder DG (2006) Neuropeptide Y and corticotropinreleasing factor bi-directionally modulate inhibitory synaptic transmission in the bed nucleus of the stria terminalis. Neuropharmacology 51(5):1013-1022. https://doi.org/10.1016/j. neuropharm.2006.06.011

41. Tasan RO, Bukovac A, Peterschmitt YN, Sartori SB, Landgraf R, Singewald N, Sperk G (2011) Altered GABA transmission in a mouse model of increased trait anxiety. Neuroscience 183:71-80. https://doi.org/10.1016/j.neuroscience.2011.03.051

42. Onakomaiya MM, Henderson LP (2016) Mad men, women and steroid cocktails: a review of the impact of sex and other factors on anabolic androgenic steroids effects on affective behaviors. Psychopharmacology 233(4):549-569. https://doi.org/10.1007/ s00213-015-4193-6

43. Oberlander JG, Henderson LP (2012) The Sturm und Drang of anabolic steroid use: angst, anxiety, and aggression. Trends Neurosci 35(6):382-392. https://doi.org/10.1016/j.tins.2012.03. 001

44. McCarthy MM (1995) Frank A. Beach Award. Functional significance of steroid modulation of GABAergic neurotransmission: analysis at the behavioral, cellular, and molecular levels. Horm Behav 29(2):131-140

45. Shekhar A (1993) GABA receptors in the region of the dorsomedial hypothalamus of rats regulate anxiety in the elevated plus-maze test .I. Behavioral measures. Brain Res 627(1):9-16

46. Shekhar A, Katner JS (1995) Dorsomedial hypothalamic GABA regulates anxiety in the social interaction test. Pharmacol Biochem Behav 50(2):253-258

47. Toth M, Fuzesi T, Halasz J, Tulogdi A, Haller J (2010) Neural inputs of the hypothalamic "aggression area" in the rat. Behav Brain Res 215(1):7-20. https://doi.org/10.1016/j.bbr.2010.05.050
48. Seo D, Patrick CJ, Kennealy PJ (2008) Role of serotonin and dopamine system interactions in the neurobiology of impulsive aggression and its comorbidity with other clinical disorders. Aggress Violent Behav 13(5):383-395. https://doi.org/10.1016/j.avb.2008. 06.003

49. Ricci LA, Rasakham K, Grimes JM, Melloni RH Jr (2006) Serotonin-1A receptor activity and expression modulate adolescent anabolic/androgenic steroid-induced aggression in hamsters. Pharmacol Biochem Behav 85(1):1-11. https://doi.org/10.1016/j. pbb.2006.06.022

50. Busardo FP, Frati P, Sanzo MD, Napoletano S, Pinchi E, Zaami S, Fineschi V (2015) The impact of nandrolone decanoate on the central nervous system. Curr Neuropharmacol 13(1):122-131. https://doi.org/10.2174/1570159X13666141210225822

51. Paoletti P, Bellone C, Zhou Q (2013) NMDA receptor subunit diversity: Impact on receptor properties, synaptic plasticity and disease. Nat Rev Neurosci 14(6):383-400. https://doi.org/10.1038/ nrn3504

52. Seamans JK, Durstewitz D, Christie BR, Stevens CF, Sejnowski TJ (2001) Dopamine D1/D5 receptor modulation of excitatory synaptic inputs to layer $\mathrm{V}$ prefrontal cortex neurons. Proc Natl Acad Sci U S A 98(1):301-306. https://doi.org/10.1073/pnas.011518798

53. Carrillo M, Ricci LA, Melloni RH (2011) Glutamate and the aggression neural circuit in adolescent anabolic steroid-treated Syrian hamsters (Mesocricetus auratus). Behav Neurosci 125(5):753-763. https://doi.org/10.1037/a0025127

54. Gardoni F, Bellone C (2015) Modulation of the glutamatergic transmission by Dopamine: a focus on Parkinson, Huntington and Addiction diseases. Front Cell Neurosci 9:25. https://doi.org/10. 3389/fncel.2015.00025

55. Kindlundh AM, Lindblom J, Nyberg F (2003) Chronic administration with nandrolone decanoate induces alterations in the genetranscript content of dopamine $\mathrm{D}(1)$ - and $\mathrm{D}(2)$-receptors in the rat brain. Brain Res 979(1-2):37-42

56. Gies U, Theodosis DT (1994) Synaptic plasticity in the rat supraoptic nucleus during lactation involves GABA innervation and oxytocin neurons: a quantitative immunocytochemical analysis. J Neurosci 14(5 Pt 1):2861-2869

57. Ehrnborg C, Rosen T (2009) The psychology behind doping in sport. Growth Hormon IGF Res 19(4):285-287. https://doi.org/ 10.1016/j.ghir.2009.04.003

58. Bueno A, Carvalho FB, Gutierres JM, Lhamas C, Andrade CM (2017) A comparative study of the effect of the dose and exposure duration of anabolic androgenic steroids on behavior, cholinergic regulation, and oxidative stress in rats. PLoS One 12(6):e0177623. https://doi.org/10.1371/journal.pone.0177623 